\title{
THE KARYOTYPE OF TRICHOBILHARZIA FRANKI MÜller et KimMig, 1994 (Digenea: SChISTOSOMATIDAE), A NEW EUROPEAN SCHISTOSOME AGENT OF SWIMMERS'ITCH
}

\author{
ŠPAKULOVÁ M.*, HORÁK P.** \& MÜLLER V.***
}

\section{Summary :}

Chromosome characteristics of Trichobilharzia franki Müller et Kimmig, 1994, causing swimmer's itch in the Western Germany, were described and compared with the karyotype of the sympatric species Trichobilharzia szidati Neuhaus, 1952. Karyotypes of both species are very similar: diploid sets consist of seven pairs of autosome chromosomes and one pair of sex chromosomes $(2 n$ $=16, n=5 m+2 s m+Z s m / W s t)$, the sex determining mechanism is ZZ in males and ZW in females and gross morphology of autosome pairs does not differ markedly. The only clear discriminative feature lies in the size and shape of sex chromosomes

KEY WORDS : Trichobilharzia franki, karyotype, schistosome.
Résumé : LE CARYOTYPE DE TRICHOBILHARZIA FRANKI MÜLLER ET KimMing, 1994 (Digenea: SCHISTOSOMATIDAE), UN NOUVEL AGENT SCHISTOSOMAL DE LA DERMATIDE DES BaIGNEURS EN EUROPE

Les caractéristiques chromosomiques de Trichobilharzia franki Müller et Kimming, 1994, agent de la dermatide des baigneurs en Allemagne de l'Ouest, ont été décrites et comparées avec le caryotype de l'espèce sympatrique Trichobilharzia szidati Neuhaus, 1952. Les caryotypes des deux espèces sont très proches: la série diploïde consiste en sept paires de chromosomes autosomaux et une paire de chromosomes sexuels $12 n=16, n$ $=5 m+2 s m+Z s m / W s t)$, le mécanisme de la détermination $d u$ sexe est ZZ chez les males et ZW chez les femelles et la morphologie générale des paires autosomales ne diffère pas considérablement. Le seul caractère distinctif clair se situe au niveau de la taille et la forme des chromosomes sexuels.

MOTS CLÉS : Trichobilharzia franki, caryotype, schistosome

\section{INTRODUCTION}

$\longrightarrow$ ercariae of bird schistosomes are known to be able to enter the human skin and cause cercarial dermatitis. The species spectrum of these agents needs to be clarified. Except the vaguely characterized species Trichobilharzia ocellata (La Valette, 1853), T. szidati Neuhaus, 1952 was considered to be the major causal organism of cercarial dermatitis in Central Europe (Kolárová et al., 1992). A newly recognized agent of European swimmer's itch - the bird schistosome T. franki - was described by Müller and Kimmig (1994). Ocellate furcocercariae of T. franki were found to be released from the snail intermediate host Radix auricularia living in "Tunisee " near Freiburg, Germany. Since then, T. franki has also been detected in Bohemia (Kolárová and Horák, unpublished). Therefore, T. franki occurs sympatrically with the common bird schistosome T. szidati. Although

\footnotetext{
* Parasitological Institute, Slovak Academy of Sciences, Hlinkova 3, 04001 Košice, Slovak Republic.

** Department of Parasitology, Charles University, Viničná 7, 12844 Prague, Czech Republic.

*** Department of Parasitology, Institute of Zoology, University of Hohenheim, Emil-Wolff-Straße 34, D-70599 Stuttgart, Germany.

Correspondence: Marta Špakulová.
}

cercariae of the two congeners can hardly be distinguished from each other, the morphological and biological features of eggs and adult worms allow their discrimination. The most distinct differences are associated with the shape of eggs, the form and reciprocal position of digestive and sexual organs of adult worms and the localization of adults within the definitive host - dwarf mallard (Anas platyrbynchos L.). The intermediate host of $T$. franki is the lymnaeid snail $R$. auricularia, while that of T. szidati is represented by Lymnaea stagnalis, $L$. peregra, $R$. auricularia and Stagnicola palustris (Neuhaus, 1952, Blair and Islam, 1983, Kolárová et al., 1992, Koláł̌ová and Horák, 1996). The aim of the present paper was to describe the karyotype of $T$. franki and to compare its chromosomal set with those of congeneric species, above all $T$. szidati.

\section{MATERIALS AND METHODS}

I ntramolluscan larval stages of T. franki, isolated from four naturally infected intermediate hosts R. auricularia coming from Tunisee near Freiburg, Germany, were used for the cytogenetic analysis. Dissected digestive snail glands, containing daughter sporocysts and developing cercariae, were treated with 
$0.005 \%$ colchicine in physiological saline for 3 hours, transferred to distilled water for hypotonic treatment for 30 minutes and subsequently fixed in cold methanol-acetic acid (3:1) for 20 minutes. Chromosome preparations were made using the air-drying technique according to Short and Grossman (1981). For conventional karyotype analysis, the slides were stained with $4 \%$ Giemsa solution ( $\mathrm{pH}$ 6.8, $10 \mathrm{~min}$ ). Results are based on examination of 56 metaphase plates, from which 15 spreads were measured. A statistical comparison of chromosome characteristics of $T$. franki and T. szidati (using data published by Špakulová et al., 1996) was performed using Student's $t$-test $(\mathrm{P}<0.05)$.

\section{RESULTS}

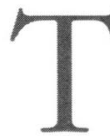
he diploid number of chromosomes of $T$. franki is $2 \mathrm{n}=16$ (Fig. 1). Seven pairs represent autosome chromosomes and one pair the sex chromosomes, $\mathrm{ZZ}$ in male (Fig. 1a) or $\mathrm{ZW}$ in female (Fig. 1b). According to the absolute length, the first pair is $9.13 \pm 2.09 \mu \mathrm{m}$ long and the 8th pair 3.32 $\pm 0.54 \mu \mathrm{m}$. The $\mathrm{Z}$ chromosome is submetacentric and slightly shorter $(8.45 \pm 2.08 \mu \mathrm{m})$ than the first largest pair of autosomes. The $\mathrm{W}$ chromosome is subtelocentric and the shortest one $(2.26 \pm 0.31 \mu \mathrm{m})$. All autosomes are of biarmed shape. The formula of the karyotype structure is $n=5 m+2 s m+Z s m / W s t$. A satellite, distinct in prometaphase but only slightly outlined in metaphase, is present on the 6th pair.

Comparing the relative lengths and centromeric indices of individual chromosome pairs of T. franki with those of $T$. szidati, some autosome chromosomes showed significant, but not very striking differences. Pairs No. $1,2,3,4,7$, and 8 differed in relative lengths between species, while pairs No. 3, 4, 5, 6, and 8 differed in centromeric indices $(\mathrm{P}<0.05$, Table I, Fig. 2). However, the only clear discriminative features lie in the size of sex chromosomes. In T. franki, the $\mathrm{W}$ is twice as small as in T. szidati; the $\mathrm{Z}$ of $T$. franki is slightly smaller than the first autosome pair, while the $\mathrm{Z}$ of $T$. szidati is larger than all autosomes (Table I, Fig. 2). Table II shows literature data on the other Trichobilharzia species which were studied cytogenetically.

\section{DISCUSSION}

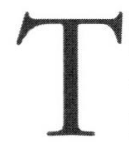

he genus Trichobilharzia comprises more than 40 species occurring worldwide (Blair and Islam, 1983). Two bird species T. ocellata (La Valette, 1853) and T. szidati Neuhaus, 1952 were considered to be the major causative agents of swimmer's itch in the Central Europe. The first of them has recently been regarded as an incompletely characterized species or species complex (Blair and Islam, 1983). The latter, T. szidati, has been thoroughly defined on a morphological and cytogenetical level (Neuhaus, 1952; Kolárová and Horák, 1996; Špakulová et al., 1996) and is experimentally studied with respect to the host/parasite immune/evasion interactions (e. g., Horák, 1995).

The description of the new species, T. franki, occurring sympatrically in natural conditions in Central Europe (Müller and Kimmig, 1994; Kolárová and Horák, unpublished) is important not only from a theoretical viewpoint but also for its practical purposes. The genetic heterogeneity of agents of schistosome dermatitis can cause differences in their virulence, pathogenicity and other medically important features. Moreover, the genetically based restriction of the larval development to a particular snail species and the knowledge of snail distribution in water bodies can help to predict the parasite species in places where cercarial dermatitis occurs.

The karyotype is one of the basic genetic characteristics of eukaryotic species. As the karyotype of T. $s z i$ dati was recently redescribed by present authors (Špakulová et al., 1996), a reliable comparison with the
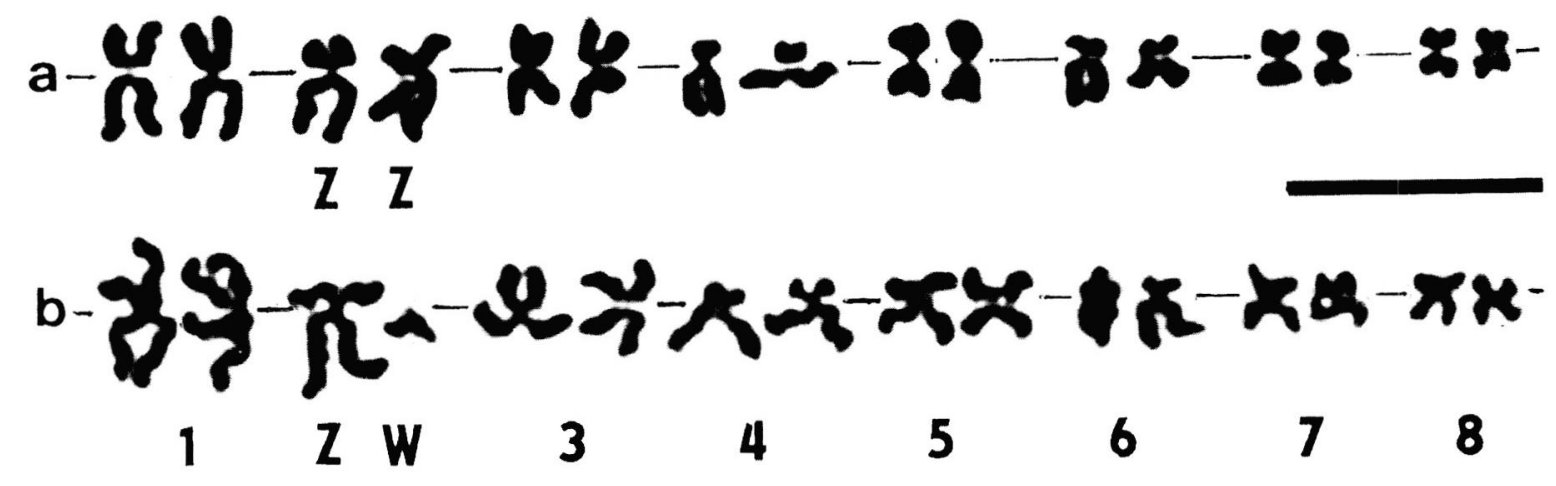

Fig. 1. - Idiogram of Trichobilharzia franki: $a:$ male, $b$ : female. bar $=10 \mu \mathrm{m}$. 


\begin{tabular}{|c|c|c|c|c|c|c|}
\hline \multirow{2}{*}{$\begin{array}{c}\text { Chromosome } \\
\text { number }\end{array}$} & \multicolumn{2}{|c|}{ Relative length (\%) } & \multicolumn{2}{|c|}{ Centromeric index } & \multicolumn{2}{|c|}{ Classification $^{a}$} \\
\hline & T. franki & T. $s z i d a t i^{b}$ & T. franki & T. szidati ${ }^{b}$ & T. franki & T. szidatib \\
\hline 1 & $19.8 \pm 0.6^{c}$ & $\begin{array}{l}\text { Z } 20.7 \pm 1.6 \\
\text { W } 9.3 \pm 1.3\end{array}$ & $45.3 \pm 2.0$ & $\begin{array}{r}\text { Z } 32.5 \pm 2.0 \\
\text { W } 37.0 \pm 2.3\end{array}$ & $\mathrm{~m}$ & $\begin{array}{c}\mathrm{Zm} \\
\mathrm{W} \mathrm{sm}\end{array}$ \\
\hline 2 & $\begin{array}{l}\text { Z } 18.3 \pm 1.0 \\
\text { W } 4.7 \pm 0.3\end{array}$ & $18.4 \pm 1.4^{c}$ & $\begin{array}{r}\text { Z } 35.8 \pm 2.4 \\
\text { W } 17.0 \pm 6.5\end{array}$ & $44.8 \pm 2.0$ & $\begin{array}{l}Z \text { Z sm } \\
\text { W st }\end{array}$ & $\mathrm{m}$ \\
\hline 3 & $13.6 \pm 0.6^{c}$ & $14.2 \pm 0.5^{c}$ & $47.6 \pm 1.8^{c}$ & $43.1 \pm 2.9^{c}$ & $\mathrm{~m}$ & $\mathrm{~m}$ \\
\hline 4 & $11.5 \pm 0.4^{c}$ & $12.4 \pm 0.7^{c}$ & $29.2 \pm 1.9^{c}$ & $27.2 \pm 2.5^{c}$ & $\mathrm{sm}$ & sm-st \\
\hline 5 & $11.3 \pm 0.6$ & $11.0 \pm 0.8$ & $47.9 \pm 2.2^{c}$ & $45.3 \pm 2.1^{c}$ & $\mathrm{~m}$ & $\mathrm{~m}$ \\
\hline 6 & $9.8 \pm 0.4$ & $9.7 \pm 0.7$ & $28.7 \pm 3.5^{c}$ & $32.3 \pm 2.8^{c}$ & $\mathrm{sm}$ & $\mathrm{sm}$ \\
\hline 7 & $8.2 \pm 0.6^{c}$ & $7.3 \pm 0.5^{c}$ & $47.6 \pm 2.9$ & $47.1 \pm 1.6$ & $\mathrm{~m}$ & $\mathrm{~m}$ \\
\hline 8 & $7.4 \pm 0.7^{c}$ & $6.5 \pm 0.6^{c}$ & $48.4 \pm 2.4^{c}$ & $41.7 \pm 3.4^{c}$ & $\mathrm{~m}$ & $\mathrm{~m}$ \\
\hline
\end{tabular}

${ }^{a}$ Nomenclature of Levan, Fredga \& Sandberg (1964); m : metacentric; sm : submetacentric; st : subtelocentric chromosomes

${ }^{b}$ Data on T. szidati published by Špakulová et al. (1996)

${ }^{c}$ Data significantly differed $(\mathrm{P}<0.05)$.

Table. I. - Comparison of chromosomal characteristics of Trichobilharzia franki and T. szidati

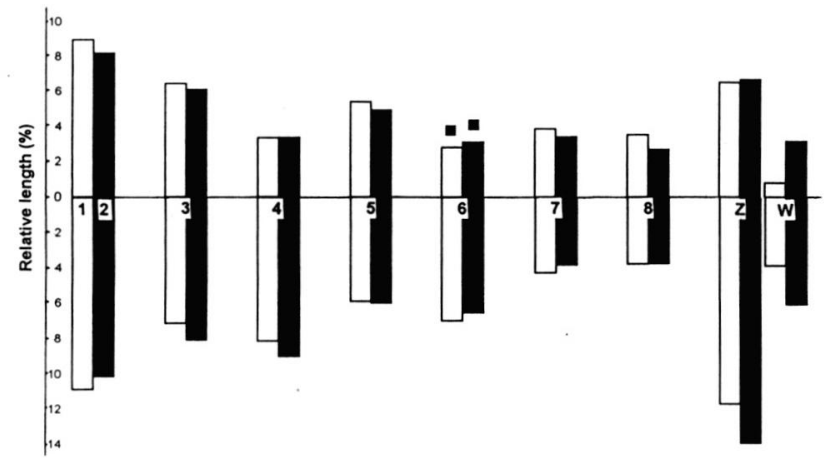

Fig. 2. - A comparison of Trichobilharzia franki (open bars) and T. szidati (black bars) idiograms.

congeneric species $T$. franki was possible using identical experimental methods.

Surprisingly, the comparison revealed similar morphology of all autosome pairs, while the most distinct differences were found in the sex chromosomes, in particular the size and shape of the W. Similar features were found in some Schistosoma species, which causes serious helminthic disease in humans and other warmblooded animals. According to Short (1983), karyotypes of seven species of the genus Schistosoma originating from Africa (i. e., S. mansoni, S. haematobium, S. intercalatum, S. rodhaini, S. bovis, S. mattheei and S. margrebowiei) are generally similar to each other and their autosome chromosomes cannot be distinguished easily. Differences among these species do occur in the sex chromosome W, which has a species-specific Cband pattern of heterochromatin. Only slight autosomal differences have been found between some pairs of species. In spite of the cytogenetical similarity, schistosomes of the S. mansoni and S. haematobium groups differ considerably in their morphology, specificity to intermediate hosts, etc. There are good reasons to expect similar features in Trichobilharzia species.

Within the family Schistosomatidae, a total of 22 species have been defined cytogenetically (Short, 1983; Baršiené, 1993). Generally, schistosome species possess relatively large, mainly biarmed chromosomes varying in number from 14 to 20 , and sex in these gonochoristic species is determined by a $\mathrm{ZZO} / \mathrm{ZW}$ \% mechanism. In the bird schistosome species of the subfamily Bilharziellinae, the $\mathrm{ZZ/ZW}$ sex determining mechanism was documented in Bilharziella polonica (Baršiené and Stanyavichyute, 1993) and T. szidati (Špakulová et al., 1996). However, no sex chromosomes were noticed in five other Trichobilharzia spp. studied cytogenetically (Table II). The other conspicuous character of Trichobilharzia spp. is a satellited chromosome pair No. 6, although it was not described in some cases (Baršiené et al., 1989; Baršiené and Stanyavichiute, 1993).

Summarizing information on karyological differences among Trichobilharzia spp. (Table II), each studied population seems to represent a unique, cytogenetically well defined species, which is quite strictly specific to its intermediate snail host. Only two karyologically distinguishable Trichobilharzia species, T. stagnicollae A and T. stagnicollae $\mathrm{B}$, parasitized the same snail host as well as the same individual. On the other hand, two populations of T. szidati from Lithuania (Baršiené and Stanyavichiute, 1993) and the Czech Republic (Špakulová et al., 1996) may represent two different species considering karyological data. 


\begin{tabular}{|c|c|c|c|}
\hline Species & Reference locality & Snail intermediate & Karyological characteristics ${ }^{a}$ \\
\hline T. physellae & $\begin{array}{l}\text { Short, Menzel, } 1960 \\
\text { USA, Michigan }\end{array}$ & $\begin{array}{l}\text { Physa parkeri, Physa sp. } \\
\text { P. magnalacustris }\end{array}$ & $\begin{array}{c}2 \mathrm{n}=16 ; \text { No. } 6 \text { satellited } \\
n=5 \mathrm{~m}+3 \mathrm{sm}\end{array}$ \\
\hline T. stagnicollae A & $\begin{array}{l}\text { Short, Menzel, } 1960 \\
\text { USA, Michigan }\end{array}$ & Stagnicola emarginata angulata & $\begin{array}{c}2 \mathrm{n}=16 ; \text { No.6 satellited } \\
\mathrm{n}=4 \mathrm{~m}+2 \mathrm{sm}+2 \mathrm{st}\end{array}$ \\
\hline T. stagnicollae $\mathrm{B}$ & $\begin{array}{l}\text { Short, Menzel, } 1960 \\
\text { USA, Michigan }\end{array}$ & Stagnicola emarginata angulata & $\begin{array}{c}2 \mathrm{n}=18 ; \text { No. } 6 \text { satellited } \\
n=5 \mathrm{~m}+4 \mathrm{sm}\end{array}$ \\
\hline Trichobilharzia sp.1 & $\begin{array}{l}\text { Baršiené et al., } 1989 \\
\text { Russia, Chukotka }\end{array}$ & Sibirenauta picta & $\begin{aligned} & 2 \mathrm{n}=18 \\
\mathrm{n}= & 7 \mathrm{~m}+2 \mathrm{sm}-\mathrm{m}\end{aligned}$ \\
\hline Trichobilharzia sp. 2 & $\begin{array}{l}\text { Baršiené et al., } 1989 \\
\text { Russia, Chukotka }\end{array}$ & Anisus acronicus & $\begin{array}{c}2 \mathrm{n}=16 \\
\mathrm{n}=7 \mathrm{~m}+1 \mathrm{sm}-\mathrm{m}\end{array}$ \\
\hline T. szidati & $\begin{array}{l}\text { Baršiené, Stanyavichyuté, } 1993 \\
\text { Lithuania }\end{array}$ & Radix (Lymnaea) ovata & $\begin{array}{c}2 \mathrm{n}=16 \\
\mathrm{n}=3 \mathrm{~m}+1 \mathrm{sm}-\mathrm{m}+3 \mathrm{sm}+1 \mathrm{st}-\mathrm{sm}\end{array}$ \\
\hline T. szidati & $\begin{array}{l}\text { Špakulová et al., } 1996 \\
\text { Czech Republic }\end{array}$ & Lymnaea stagnalis & $\begin{array}{c}2 \mathrm{n}=16 ; \text { No. } 6 \text { satellited } \\
\mathrm{n}=5 \mathrm{~m}+1 \mathrm{sm}+1 \mathrm{sm}-\mathrm{st}+\mathrm{Zsm} / \mathrm{Wsm}\end{array}$ \\
\hline T. franki & $\begin{array}{l}\text { present results } \\
\text { Germany }\end{array}$ & Radix (Lymnaea) auricularia & $\begin{array}{c}2 n=16 ; \text { No. } 6 \text { satellited } \\
n=5 m+2 s m+Z s m / W s t\end{array}$ \\
\hline
\end{tabular}

${ }^{a}$ Classification: $\mathrm{m}$ : metacentric; sm : submetacentric; st : subtelocentric chromosomes.

Table II. - Comparison of karyotypes of Trichobilharzia spp.

Blair and Islam (1983) emphasized the impact of lifecycle characteristics to distinguish Trichobilhazia spp. and paid special attention to their restricted specificity with respect to snail intermediate hosts. Therefore, a further detailed study of morphology, life cycle and genetics of avian schistosomes is needed for the identification of species within the genus Trichobilharzia.

\section{ACKNOWIEDGEMENT}

1 uthors are indebted to Ivica Král'ová, PhD., Parasitological Institute of the Slovak Academy of Sciences for her help with evaluation of cytogenetical data. Thanks are also expressed to Milena Svobodová, MSc., Charles University for providing the French translation. The work was supported by the Slovak Grant Agency VEGA (No. 2/2079/96).

\section{REFERENCES}

BarŠIEnÉ J. The Karyotypes of Trematodes. Academia Press, Moscow, 1993, 370 p.

BarŠIEnÉ J.V. \& STANYAVICHYUte G.J. Karyotypes of Trichobilharzia szidati and Bilharziella polonica (Schistosomatidae, Trematoda). Parazitologiya, 1993, 27, 41-47.

Baršiené J.V., Stanyavichyute G.J. \& Orlovskaja O.M. Karyological investigations on trematodes of the family Schistosomatidae in North-West Chukotka. Parazitologiya, 1989, 23, 496-503.

Blair D. \& Islam K.S. The life-cycle and morphology of Trichobilharzia australis n. sp. (Digenea: Schistosomatidae) from the nasal blood vessels of the black duck (Anas superciliosa) in Australia, with a rewiew of the genus Trichobilharzia. Systematic Parasitology, 1983, 5, 89-117.
HoráK P. Developmentally regulated expression of surface carbohydrate residues on larval stages of the avian schistosome Trichobilharzia szidati. Folia Parasitologica, 1995, $42,255-265$.

Kolárová L., Horák P. \& FajFrlík K. Cercariae of Trichobilharzia szidati Neuhaus, 1952. (Trematoda: Schistosomatidae): the causative agent of cercarial dermatitis in Bohemia and Moravia. Folia Parasitologica, 1992, 39, 399-400.

KolÁŘ́ová L. \& Horák P. Morphology and chaetotaxy of Trichobilharzia szidati Neuhaus, 1952 cercariae (Digenea: Schistosomatidae: Bilharziellinae). Helminthologia, 1996, 33, 3-7.

Levan A., Fredga K. \& Sandberg A.A. Nomenclature for centromeric position on chromosomes. Hereditas, 1964, 52, 201-220.

MülleR V. \& Kimmig P. Trichobilharzia franki n. sp. a causative agent of swimmer's itch in south-western Germany. Applied Parasitology, 1994, 35, 12-31.

NeuHaus W. Biologie und Entwicklung von Trichobilharzia szidati n. sp. (Trematoda, Schistosomatidae), einem Erreger von Dermatitis beim Menschen. Zeitschrift für Parasitenkunde, 1952, 15, 203-266

SHort R.B. Presidental address: Sex and the single schistosome. Journal of Parasitology, 1983, 69, 3-22.

Short R.B. \& Grossman A.I. Conventional Giemsa and Cbanded karyotypes of Schistosoma mansoni and S. rodbaini. Journal of Parasitology, 1981, 67, 661-671.

Short R.B. \& Menzel M.Y. Chromosomes of nine species of schistosomes. Journal of Parasitology, 1960, 46, 273-287.

Špakulová M., Horák P. \& Král'ová I. Karyotype of an avian schistosome Trichobilharzia szidati (Digenea: Schistosomatidae). International Journal for Parasitology, 1996, 26, 783-785.

Reçu le 12 novembre 1996 Accepté le 17 janvier 1997 